\title{
Diagnosis of machine tool with using Renishaw ball-bar system
}

\author{
Robert Čep ${ }^{1, *}$, Śárka Malotová ${ }^{1}, J i \check{r} i$ Kratochvíl ${ }^{1}$, Dana Stančeková ${ }^{2}$, Andrej Czán ${ }^{2}$, \\ Tomáš Jakab ${ }^{1}$ \\ ${ }^{1}$ Faculty of Mechanical Engineering, VŠB - Technical University of Ostrava, 17. Listopadu 15/2172 \\ 708 33, Ostrava, Czech Republic \\ ${ }^{2}$ Faculty of Mechanical Engineering, University of Zilina, Univerzitna 8215/1, 01026 Zilina, \\ Slovakia
}

\begin{abstract}
The article deals with accuracy of machine tools. The aim was to determine the accuracy with which already operates used machine - HAAS CNC Milling machine MiniMill. For evaluation of accuracy of the machine tool was used Renishaw QC20-W Ballbar system, which has the Department of Machining, Assembly and Engineering Metrology of VŠB - TUO. The theoretical part describes the measurement principle using a telescopic Ballbar system. The principle of measurement is the comparison of the actual deviation from the ideal circle which is programmed. Experimental part is focused on the diagnosis of the whole process by the direct method of measurement during changing feed rate. Specifically, the determination of circularity deviation at machine tool was in accordance with international standards, e.g. ISO 230-4.
\end{abstract}

Keywords: ball-bar system, milling machine, circularity, circularity deviation

\section{Introduction}

3-5 axis machine tools are increasingly applied in all areas of modern production. The main criterion of these machine tools is production of accurate components. This may be achieved under controlled process. Accuracy and reliability of the machine tools are in the first place. Many users think that buying expensive machine tool achieves a high quality production. Complex accuracy of machine tool is dependent on the geometric accuracy of the individual components of machine tool and on the toughness all the system. Identification, description and elimination of sources of error can improve the final working accuracy of machine tool. For these sources of error can be considered kinetic and thermo mechanical errors loads, dynamic forces, imperfection and deviation from individual functional parts of machine tools and their wear. Last but not least, there is an emphasis on the correct choice of machine strategy, cutting conditions, cutting tools and material of workpieces $[1,2]$.

Accuracy of machining can be characterized as degree of compliance of machined parts with its geometrical pattern on drawing. The agreement is bigger, so the accuracy of

\footnotetext{
* Corresponding author: rober.cep@vsb.cz

Reviewers: Marcin Kubiak, Ivan Kuric
} 
machining is higher. On the other hand, relevant deviation (error) represents degree of compliance of part with geometrical pattern - inaccuracy. So that component could fulfil its function for which is specified, its real shape and surface have to deviate from ideal shape in definite acceptable limits. These limits are defined as deviations shape, position, dimensions from nominal values and surface roughness $[3,4]$.

\section{Accuracy of machine tools}

Diagnostic accuracy of machine tools is very important, and therefore is even bigger effort of service technician to approach the desired tolerances every thousandth of a millimetre. The machine tools are before putting on production process, submit tests geometric and working accuracy on the basis of standards ČSN ISO 230 - Test code for machine tools. Machine tools are under certain loading conditions and thanks these tests can be detected deficiencies, which have effect on functioning of the machine tools [5].

\subsection{Test code for machine tools - part 4: circular tests for numerically controlled machine tools}

Circular test is described by standards ISO 230-4. To determine the circular interpolation follow two methods.

Direct method - determination of accuracy of cylindrical surface milled at the workpiece with minimal removal of material. The principle of the method is the measurement of accuracy of a circle of the certain radius on the workpiece using the CMM. The advantage of this method is high accuracy of acquired results. The main disadvantage is duration causes by machining and measurement. Direct method of circular test gives to us fast results. For this test is chosen special device connected with control system of machine tool.

The main disadvantage of indirect method is that cutting forces which can cause inaccuracies of the machine tool during machining are not reflected in the measurement. Between other standards dealing with circular interpolation, can be classified ASME B5.54, ASME B5.57 (GB) or JIS B6194 (Japan) [5, 6].

Circularity deviation is one of deviation of shape and position. Real surfaces show deviation given nominal values. In this tolerance field must be the actual element. Circularity deviation is the biggest perpendicular distance measured to envelope circle (see Fig. 1).

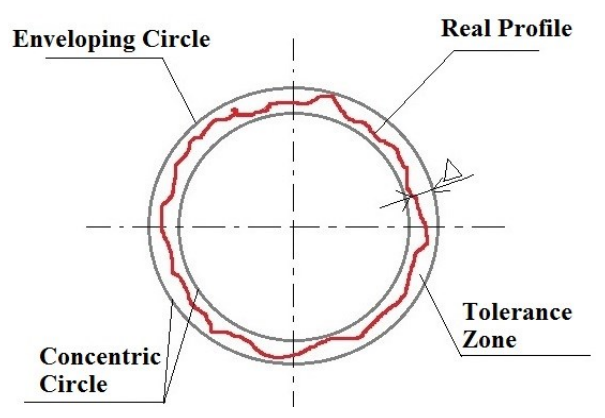

Fig. 1. Circularity Deviation [5]

Circularity deviations are measured with special touch device, which rotates around fixed component, respectively conversely or used CMM. Circularity deviation $(\Delta)$ of points of actual profile of enveloping circle is the biggest distance. These deviations together with 
surface roughness significantly influence the level of vibration of rotating parts, hence they need to be properly diagnosed and improving the whole process of production. The experiment on diagnosis of accuracy of machine tool was realized with using Ball-Bar system from Renishaw Company [3].

\section{Measurement of accuracy}

The aim of the article was to evaluate the accuracy with which operates the machine tool, HAAS CNC MiniMill, which is commonly used for the production of the medium-sized components. This vertical milling center operates with power $5.6 \mathrm{~kW}$. Maximum speed is $6000 \mathrm{rpm}$, working range of axis X/Y/Z is (406/305/254) mm. Diagnosis of accuracy of machine tool was evaluated on the basis Ball-Bar system QC20 - W. The device operates on the principle of circular interpolation using the direct method. The measuring of accuracy of machine tool was realized in central position, which is common used for machining of parts. Given small range of working table was not possible to apply the system in more position. In our case the circularity deviation was evaluated on unloaded machine in the XY plane at 5 different feed rates (see below). The Ball-Bar system was purchased by the Department of Machining, Assembly and Engineering Metrology, Faculty of Mechanical Engineering, VŠB - TUO.

Table 1. Measurement parameters

\begin{tabular}{|c|c|c|c|c|}
\hline $\mathbf{v}_{\mathbf{f 1}}$ & $\mathbf{v}_{\mathbf{f} 2}$ & $\mathbf{v}_{\mathbf{f 3}}$ & $\mathbf{v}_{\mathbf{f} 4}$ & $\mathbf{v}_{\mathbf{f 5}}{ }^{\mathbf{1}}$ \\
\hline $1000 \mathrm{~mm} \cdot \mathrm{min}^{-1}$ & $2000 \mathrm{~mm} \cdot \mathrm{min}^{-1}$ & $3000 \mathrm{~mm} \cdot \mathrm{min}^{-1}$ & $4000 \mathrm{~mm} \cdot \mathrm{min}^{-1}$ & $5000 \mathrm{~mm} \cdot \mathrm{min}^{-1}$ \\
\hline
\end{tabular}

\subsection{Diagnosis by system ballbar QC20 - W}

System Ball-Bar QC20 - W falls into a group of telescopic systems from Renishaw using for analysis accuracy CNC machine tools. The ball bar is a very high accuracy, telescoping linear sensor with precision balls at each end. The machine performs two consecutive circular arcs (clockwise - CW and counter clockwise - CCW) in any one of the machines test planes (XY, YZ, ZX) and very accurately measures any variations in the test circle radius traced by the machine during the test. Software then analyses the measured data to give results in accordance with various international standards $[1,6]$.

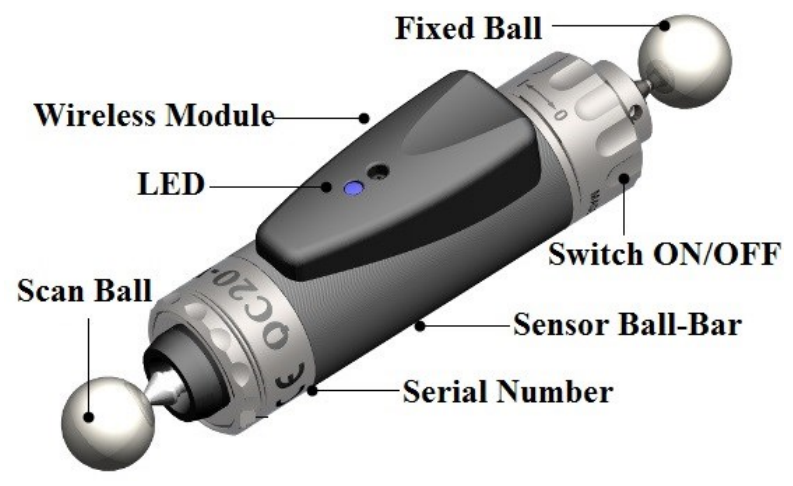

Fig. 2. Sensor Ball-Bar [7]

Figure 2 shows the sensor Ball-Bar. The set also includes extension with lengths of 50, 150 , and $300 \mathrm{~mm}$. Ball holder allows testing in free orthogonal planes without moving the central pivot. Table 2 shows technical parameters of system Ball-Bar. 
Table 2. Technical parameters of system Ball-Bar [7]

\begin{tabular}{|l|l|}
\hline \multicolumn{2}{|l|}{ Technical parameters of system Ball-Bar } \\
\hline Sensor resolution & $0.1 \mu \mathrm{m}$ \\
\hline Ball-Bar measurement accuracy & $\pm\left(0.7+0.3 \% \mathrm{~L}^{*}\right) \mu \mathrm{m}$ \\
\hline Ball-Bar software measurement range & $\pm 1.0 \mathrm{~mm}$ \\
\hline Stroke sensor & $-1.25 \mathrm{~mm}$ to $+1.75 \mathrm{~mm}$ \\
\hline Max. scanning rate & $1000 \mathrm{~Hz}$ \\
\hline Transmission range (Bluetooth) & typically $10 \mathrm{~m}$ \\
\hline Dimensions & $(395 \times 300 \times 105) \mathrm{mm}$ \\
\hline Weight system & $3.75 \mathrm{~kg}$ \\
\hline
\end{tabular}

*L - length of measuring errors

For evaluation of deviation was used standard ISO $230-4$. All analysis was in the form of a graphical report, which specifically states of size of deviation. For connection of the system with machine tool we used Bluetooth connectivity. We created program for acquisition of data. The machine tool had to draw the circle 2times in clockwise $(\mathrm{CW})$ and 2 times counter clockwise $(\mathrm{CCW})$. The resulting deviations were drawn in report. As shown in figure $3 \mathrm{a}$, scanning data was taken place in second phase - after covering $180^{\circ}$, scanning arc $\left(360^{\circ}\right)$. Figure $3 \mathrm{~b}$ shows setting o system Ball-Bar.

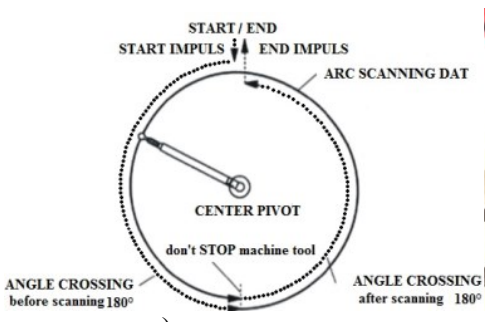

a)

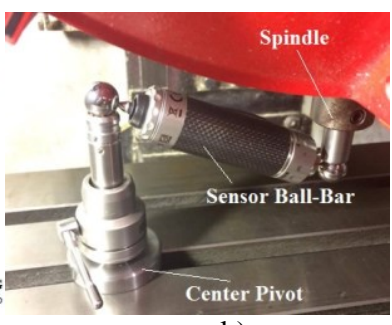

b)

Fig. 3. (a) Arc scanning data; (b) ball-bar sensor clamped in machine tool

\section{Results of measurement}

The values measured using a system Ball-Bar were evaluated based on ISO $230-4$. Table 2 shows deviations in clockwise. For each feed rate measurement was performed four times.

Table 3. Measured deviation ISO $230-4(\mathrm{CW})[3]$

\begin{tabular}{|c|c|c|c|c|c|}
\hline \multicolumn{6}{|c|}{ FEED RATE $v_{f}\left[\mathrm{~mm} \cdot \mathrm{min}^{-1}\right]$} \\
\hline & 1000 & 2000 & 3000 & 4000 & 5000 \\
\hline no. & \multicolumn{5}{|l|}{$\Delta[\mu \mathrm{m}]$} \\
\hline 1 & 10.50 & 10.50 & 10.40 & 11.40 & 19.80 \\
\hline 2 & 10.40 & 10.40 & 10.40 & 11.20 & 19.50 \\
\hline 3 & 10.20 & 9.80 & 10.20 & 10.50 & 18.70 \\
\hline 4 & 10.60 & 9.30 & 10.30 & 10.10 & 19.30 \\
\hline $\bar{\Delta}_{[\mu \mathrm{m}]}$ & $(10.43 \pm 0.17)$ & $(10.00 \pm 0.56)$ & $(10.33 \pm 0.10)$ & $(10.55 \pm 0.47)$ & $(19.33 \pm 0.47)$ \\
\hline
\end{tabular}


The resulting circularity deviation for feed rate $(1000-4000) \mathrm{mm} \cdot \mathrm{min}^{-1}$ achieves almost constant values - about $10.5 \mu \mathrm{m}$. For feed rate $2000 \mathrm{~mm} \cdot \mathrm{min}^{-1}-$ deviation for third and fourth measurement descends by $1 \mu \mathrm{m}$. Overall, the greatest measured value was during the highest testing feed rate $-5000 \mathrm{~mm} \cdot \mathrm{min}^{-1}$. The deviation was double $\Delta=(19.33 \pm 0.47) \mu \mathrm{m}$.

Figure 4 shows four shapes for measuring of accuracy of machine tool in clockwise for feed rate $2000 \mathrm{~mm} \cdot \mathrm{min}^{-1}$. In third and fourth case you can see these changes of deviation size.
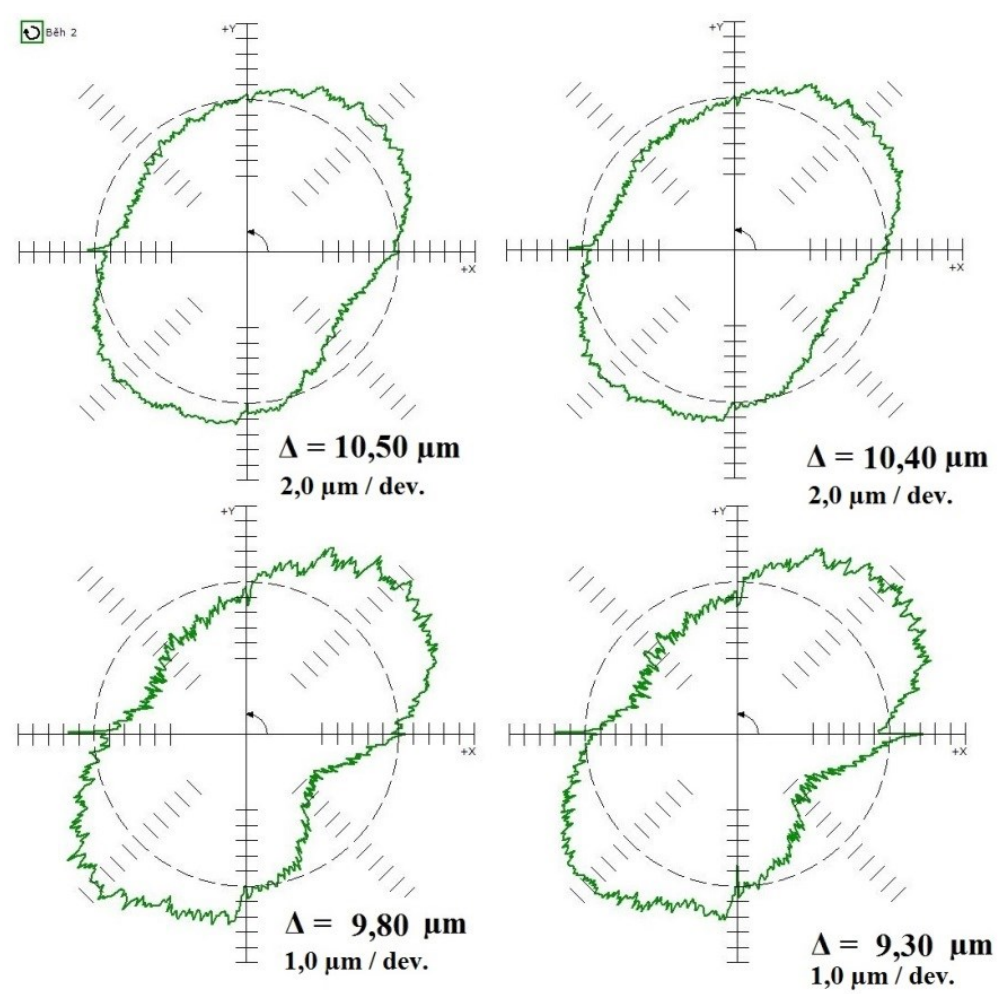

Fig. 4. Circularity Deviation - Clock Wise $-\mathrm{v}_{\mathrm{f}}=2000 \mathrm{~mm} \cdot \mathrm{min}^{-1}$

Table 4. Measured deviation ISO $230-4(\mathrm{CCW})[3]$

\begin{tabular}{|c|c|c|c|c|c|}
\hline \multicolumn{6}{|c|}{ CCW - COUNTER CLOCK WISE } \\
\hline \multicolumn{6}{|c|}{ FEED RATE $v_{\mathrm{f}}\left[\mathrm{mm} \cdot \mathrm{min}^{-1}\right]$} \\
\hline & 1000 & 2000 & 3000 & 4000 & 5000 \\
\hline no. & \multicolumn{5}{|l|}{$\Delta[\mu \mathrm{m}]$} \\
\hline 1 & 10.00 & 10.30 & 10.20 & 11.40 & 18.40 \\
\hline 2 & 10.10 & 10.10 & 9.90 & 10.80 & 19.80 \\
\hline 3 & 9.90 & 10.10 & 10.10 & 10.40 & 18.80 \\
\hline 4 & 10.00 & 9.90 & 10.10 & 10.60 & 19.00 \\
\hline $\bar{\Delta}_{[\mu \mathrm{m}]}$ & $(10.00 \pm 0.08)$ & $(10.10 \pm 0.16)$ & $(10.08 \pm 0.13)$ & $(10.80 \pm 0.43)$ & $(19.03 \pm 0.58)$ \\
\hline
\end{tabular}

Table 3 shows values of the deviations in the same conditions, but in counter clockwise. Measured values for feed rate $(1000-3000) \mathrm{mm} \cdot \mathrm{min}^{-1}$ have almost constant progress 
again. The average deviation with increasing feed rate increased linearly. The big change was measured for feed rate $5000 \mathrm{~mm} \cdot \mathrm{min}^{-1}-\Delta=(19.03 \pm 0.58) \mu \mathrm{m}$. Figure 5 shows again shapes of deviations for the same feed rate, but in counterclockwise (CCW) for comparison with the previous case.
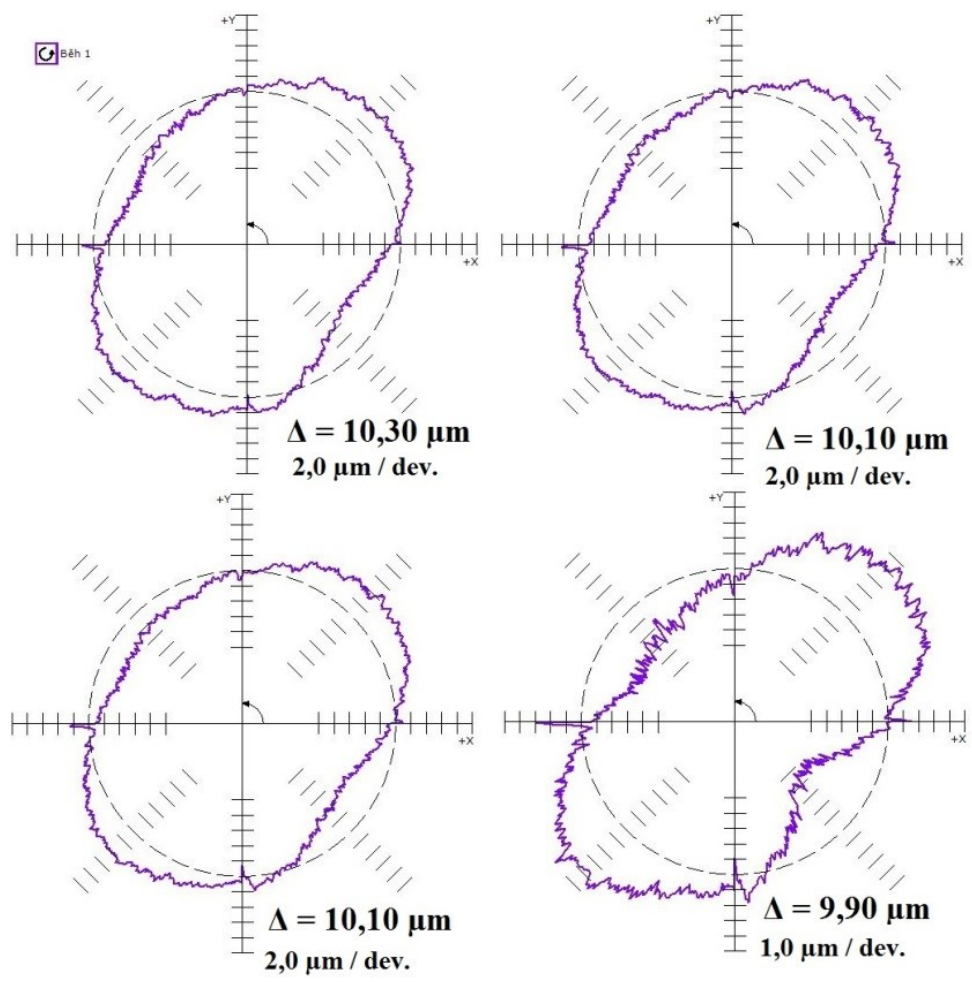

Fig. 5. Circularity Deviation - Counter Clock Wise $-\mathrm{v}_{\mathrm{f}}=2000 \mathrm{~mm} \cdot \mathrm{min}^{-1}$

\section{Conclusion}

At companies are nowadays high demands on the accuracy of manufactured parts. One of the ways to achieve prescribed parameters is to keep machine tools in good condition and continuously evaluate his situation. Only machine tools, which comply with predetermined amount of deviation, may be used for final machining and ensures of production in tolerances. A suitable solution would be to use measuring system Renishaw Ball-Bar QC20 - W, when the machine tool is measured in the unloaded condition and monitored circularity deviation from ideal circle. The advantage is the evaluation according to variety of standards.

The aim of article was to determine accuracy of the selected milling machine HAAS MiniMill. Circularity deviations were evaluated in plane XY during unloaded phase of machine tool. The measuring equipment was put in the central of machine tool, because the most of workpieces are situated here for machining. It was set five different feed rates from 1 to $5 \mathrm{~m} \cdot \mathrm{min}^{-1}$. For individual feed rate was detected circularity deviation in clockwise and counter clockwise. All measurements were measured always 4times at the same parameters and calculated arithmetic mean and standard deviation. In the both cases (CW and CCW) were evaluated, that with increasing feed rate, to value $4000 \mathrm{~mm} \cdot \mathrm{min}^{-1}$, circularity deviations were on the same level. With feed rate $5000 \mathrm{~mm} \cdot \mathrm{min}^{-1}$, circularity deviation 
increased sharply up to twice the amount (see in fig. 6). The accuracy of machine tool and machined surface decreased with this value of feed rate. This machine tool is suitable to use for finishing operations for feed rates up to $4 \mathrm{~m} \cdot \mathrm{min}^{-1}$. At higher feed rates only use on roughing or preparatory operations.

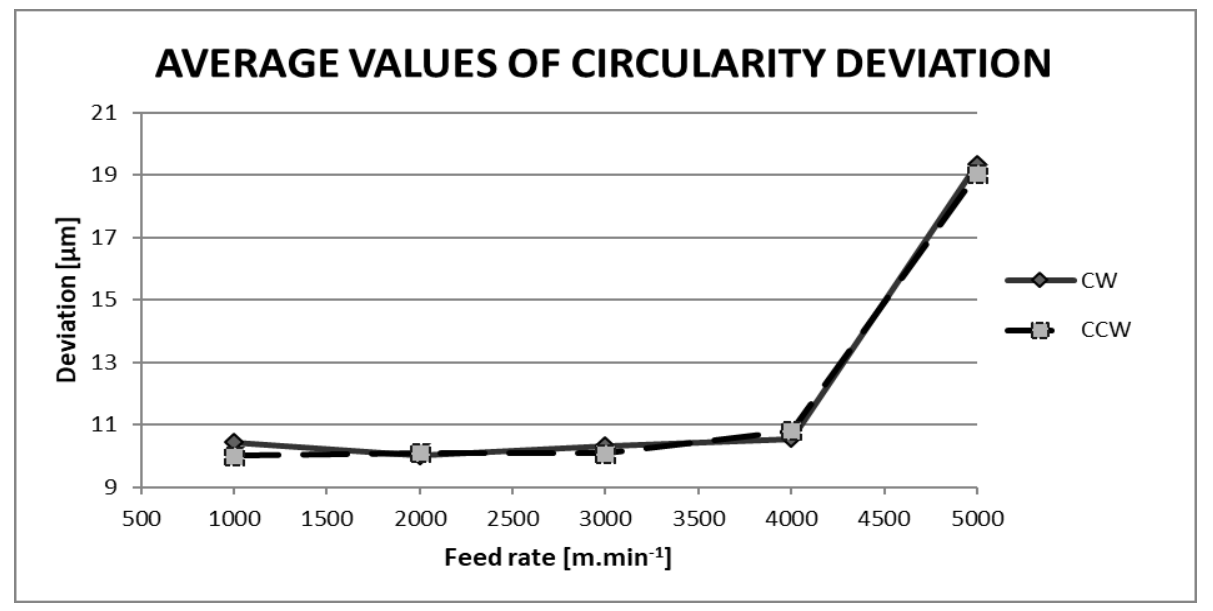

Fig. 6. Scheme of the average $\mathrm{CW}$ and $\mathrm{CCW}$ deviations

Article has been done in connection with projects Education system for personal resource of development and research in field of modern trend of surface engineering - surface integrity, reg. no. CZ.1.07/2.3.00/20.0037 financed by Structural Founds of Europe Union and from the means of state budget of the Czech Republic and by project Students Grant Competition SP2016/172 and SP2016/174 financed by the Ministry of Education, Youth and Sports and Faculty of Mechanical Engineering VŠB-TUO.

\section{References}

1. J. Dekan, Diagnostic equipment for monitoring of manufacturing machines. Strojárstvo /Strojírenství: Stroje a technológie [online] [cit. 2016-04-08] http://www.engineering.sk/index.php/clanky2/stroje-a-technologie/546-diagnostickezariadenia-monitorujuce-stav-obrabacich-strojov (2012)

2. H. Schwenke, et al., Geometric error measurement and compensation of machines-An update. ELSEVIER - Manufacturing Technology 16 (57), (2008)

3. T. Jakab, Diagnostics of machining equipment by using of Renishaw system QC20-W BALLBAR. Ostrava, Diploma thesis. VŠB - TUO (2015)

4. P. Demeč, Accuracy of manufacturing machines and their mathematical modelling. (Edícia vedeckej a odbornej literatúry - SjF TU v Košiciach, Vienala Košice, 15-28, ISBN 80-7099-620-X, 2001)

5. ČSN ISO 230- 4. Zásady zkoušek obráběcich strojů: - část 4: zkoušky kruhové interpolace u čislicově ř́zených obráběcích strojů. (2010)

6. M. Beňo, Circular interpolation and positioning accuracy deviation measurement on five axis machine tools with different structures. Technical Gazette 20 (3), 6, ISSN 1330-3651 (2013)

7. Ball bar testing explained. [online] Renishaw plc. [cit. 2016-04-08] Available at: http://www.renishaw.com/en/ballbar-testing-explained--6818 (2001) 